\title{
Leaf shrinkage: a predictive indicator of the potential variation of the surface area-to-volume ratio according to the leaf moisture content
}

\author{
Salaheddine Essaghi ${ }^{1}{ }^{2 *}$, M'hamed Hachmi $^{2}$, Mohammed Yessef ${ }^{1}$ and Mohammed Dehhaoui ${ }^{1}$
}

${ }^{*}$ Correspondence:

s.essaghi@gmail.com

${ }^{1}$ Institut Agronomique et Vétérinaire Hassan II, BP

6202, Rabat-Instituts, Rabat, Morocco

Full list of author information is available at the end of the article

\begin{abstract}
Leaf shrinkage provides insights into the potential variation of foliar SVR, within the same species, when leaf moisture content is changing in response to water deficit. Since SVR is among the most significant plant flammability features, leaf shrinkage would be a relevant component of fuel hazard assessment through its influence on SVR, enhancing - if it is taken into account - thereby the wildfire prediction accuracy. The purpose of this work is, first, to consider the leaf shrinkage by characterizing the plant species towards the shrinkability of their leaves, taking account the possible site effect, to characterize the behavior of shrinkage as a function of moisture content and finally to perform a classification for some dominant Mediterranean species based on the shrinkage levels. The assessment of the hierarchical relationships between the dimensional shrinkages is also aimed. Leaves and needles of thirteen tree and shrub species were harvested from six different sites in western Rif Mountains. Leaves dimensions and moisture content were measured regularly during a gradual drying at the laboratory. Dimensional shrinkages were calculated at each moisture content level. Dimensional shrinkages behaved similarly whether in leaf or timber and kept the same reporting relationships between each other. Among the species sampled in different sites, site effect is significant only in Pinus canariensis and Pistacia lentiscus. A classification of the plant species was carried out in three separate classes. Generally, shrinkage class of the plant species studied gave an idea on its flammability ranking reported in the literature, implying thus a cause-and-effect relationship between both parameters.
\end{abstract}

Keywords: Dimensional shrinkage, Leaves and needles, Foliar SVR

\section{Background}

Fire risk assessment requires a realistic flammability ranking of the forest species (Dimitrakopoulos 2001), which is a relevant component of forest fire management (Dimitrakopoulos 2001; Valette 1990; Liodakis et al. 2008). Wildfires occurrence is governed by several parameters. Vegetation can either increase fire intensity or act as a heat sink and mitigate the fire size (Pellizzaro et al. 2007).

Surface area-to-volume ratio is the best descriptor of fuel particle size (Dimitrakopoulos and Panov 2001; Fernandes and Rego 1998; Hachmi et al. 2011a). Besides being 
widely used in most of fire behavior prediction systems, it is often introduced as a significant factor of plant species flammability (Fernandes and Rego 1998; Papió and Trabaud 1990; White and Zipperer 2010). Surface area-to-volume ratio (SVR) is also a critical plant property, considered as central to fuel characterization and fire risk assessment (Fernandes and Rego 1998; Hachmi et al. 2011a). SVR varies not only from a species to another-as reported in the literature-(Dimitrakopoulos and Panov 2001; Fernandes and Rego 1998; Hachmi et al. 2011a; Papió and Trabaud 1990; Hernando et al. 1995; Pereira et al. 1995) but within the same species, it is also influenced by the leaf moisture content especially foliar SVR, since leaf thickness [major element of SVR (Hachmi et al. 2011a)] is strongly correlated with moisture content (Búrquez 1987; Bacelar et al. 2004). Indeed, leaf thickness decreases when moisture content decreases (Búrquez 1987) and according to SVR computing formula (Hachmi et al. 2011a), SVR rises making the plant material even more flammable. Thus, leaf thickness variation could significantly affect the flammability of the species and therefore must be taken into account in plant flammability assessment in order to enhance the efficiency of the fuel hazard prediction models. Thickness variation range can be better approached from the "leaf shrinkage" concept by drawing upon the wood shrinkage concept that is among the most important wood properties. Thus, the more important the leaf shrinkage is, the higher the potential increase of SVR will be. No report has previously considered the leaf shrinkage parameter during the evaluation of the pyric properties of plant species. The importance of the leaf shrinkage is its contribution in SVR variation, so modifying one of the most significant pyric properties. Besides, given that leaf shrinkage depends on thickness variation as a response to water deficit, it can be a means of assessing water status of the plant in xeric conditions, since thicker leaves contain a greater volume of water (Bacelar et al. 2004). The assessment of this parameter would be relevant to fuel hazard rating (Alexander and Cruz 2012; Pausas et al. 2012).

Otherwise, leaf shrinkage is the combination of dimensional shrinkages following the three dimensions of the leaf (thickness, width and length). It would make sense, therefore, if we studied leaf shrinkage with regard to its three components. In addition, given that leaf shrinkage is highly influenced by the moisture content, this cause-and-effect relationship may be also affected by site effect since leaf moisture content is governed by the ecological factors (Papió and Trabaud 1990).

The aim of this work is, first, to characterize plant species by their leaf shrinkage potential and its dimensional ranges and then, to assess the possible effect of site on leaf shrinkage and to characterize the behavior of shrinkage as a function of moisture content. The next objective is to classify the forest fuels examined based on their potential leaf shrinkage.

\section{Methods}

\section{Study sites}

Six sites were located throughout northwestern Morocco (western Rif Mountains). Each site had experienced no fires for at least 3 years and contained a suite of canopy and understory species characterizing the respective ecosystems. All the study sites are properties managed by the Moroccan High Commission for Forests and gather forests of Larache, Ahl Srif and Souk L'Qolla (Larache province), Tanaqoub, Dardara 
(Chefchaouen province) and Bellota forest (Ouezzane province) (Table 1). Each site was chosen according to an altitudinal gradient starting at the cork oak forests (Atlantic coast) to pine forests of Chefchaouen and in a purpose to cover most tree and shrub species.

\section{Species selection and sampling}

Canopy and understory species were chosen based on their abundance in the ecosystems of Western Rif. The tree species studied were Pinus pinea (stone pine), Pinus pinaster (maritime pine), Pinus canariensis (Canary Island pine), Ceratonia siliqua (carob tree), Quercus suber (cork oak) and Quercus coccifera (kermes oak). Shrub species were Arbutus unedo (strawberry tree), Cistus albidus (grey-leaved cistus), Cistus crispus (wrinkle-leaved rockrose), Cistus monspeliensis (narrow-leaved cistus), Cistus salviifolius (sage-leaved rockrose), Pistacia lentiscus (mastic tree) and Viburnum tinus (laurustinus) (Table 1).

The species were selected according to their availability at the site. The samples were harvested in August 2014. Because leaves are considered the most flammable parts of the plants (Dimitrakopoulos and Papaioannou 2001), only leaves and needles were collected. To eliminate the possible effect of age, six leaves or needles samples of different size and morphologies were selected from each species and at each sampling site. A total of 120 leaves and 30 needles was harvested from the sites, placed into sealed plastic bags and transported in a cooler with ice. Samples were monitored at the Laboratory of Wildfire Research, Ecole Nationale Forestière d'Ingénieurs located in Salé, Morocco.

\section{Samples physical characteristics and moisture content monitoring}

Once in the laboratory, measurements concerning length, width, thickness and weight of the live fresh foliage samples were taken as Hachmi's et al. method (2011a). To assess the shrinkage variability of the samples depending on their moisture content, sample dimensions were monitored during their progressive drying. Samples were therefore placed inside papers and pressed the first days of drying, in order to keep their initial shape and still adapted to size measurements even dry. Dimensions and weight measurements are repeated at regular intervals until the samples dried. During the air-drying period, the first days when the drying rate is high, the morphological and weight measurements are taken every $12 \mathrm{~h}$. Later, as the air-drying rate decreases appreciably, the measurements are performed every $24 \mathrm{~h}$. Once the samples are completely air-dried, and in an objective

Table 1 Distribution of the harvested species among sampling sites

\begin{tabular}{|c|c|c|c|c|}
\hline Sampling sites & Altitude (m) & Longitude $\mathrm{N}$ & Latitude W & Species harvested \\
\hline Larache & 25 & $35^{\circ} 13^{\prime} 45.9^{\prime \prime}$ & $6^{\circ} 14^{\prime} 25.0^{\prime \prime}$ & Q. suber, P. pinea, C. salviifolius \\
\hline Ahl Srif & 142 & $35^{\circ} 00^{\prime} 18.1^{\prime \prime}$ & $5^{\circ} 41^{\prime} 26.5^{\prime \prime}$ & $\begin{array}{l}\text { P. canariensis, C. monspeliensis, C. siliqua, C. crispus, P. } \\
\text { lentiscus, Q. suber }\end{array}$ \\
\hline Souk L'Qolla & 263 & $35^{\circ} 5^{\prime} 2.5^{\prime \prime}$ & $5^{\circ} 34^{\prime} 19.5^{\prime \prime}$ & $\begin{array}{l}\text { P. pinaster, A. unedo, C. albidus, C. monspeliensis, C. } \\
\quad \text { siliqua, P. lentiscus }\end{array}$ \\
\hline Tanaqoub & 615 & $35^{\circ} 7^{\prime} 2.7^{\prime \prime}$ & $5^{\circ} 26^{\prime} 59.1^{\prime \prime}$ & Q. suber, C.monspeliensis \\
\hline Dardara & 406 & $35^{\circ} 7^{\prime} 50.0^{\prime \prime}$ & $5^{\circ} 17^{\prime} 23.7^{\prime \prime}$ & P. canariensis, A. unedo, P. lentiscus, Q. suber \\
\hline Bellota & 128 & $34^{\circ} 56^{\prime} 5.0^{\prime \prime}$ & $5^{\circ} 31^{\prime} 56.1^{\prime \prime}$ & P. canariensis, C. monspeliensis, V. tinus, Q. coccifera \\
\hline
\end{tabular}


to reach, progressively, very low levels of humidity feigning dead foliage and litter moisture content, the samples were placed in the oven gradually at different ascending temperatures $\left(30,35,40,50\right.$ and $\left.60^{\circ} \mathrm{C}\right)$ during $24 \mathrm{~h}$ for each oven temperature. At each oven temperature, the same latter measurements (thickness, width, length and weight) are carried out. Weights obtained after oven-drying samples at $60{ }^{\circ} \mathrm{C}$ during $24 \mathrm{~h}$ are considered as the samples oven-dry weight that will establish a base of calculation of the samples moisture contents during all drying stages.

Moisture content of each sample was computed based on oven-dry weight (Behm et al. 2004) as follows:

$$
\text { Moisture content }(\%)=\frac{\text { fresh instant weight }- \text { ovendry weight }}{\text { ovendry weight }} \times 100
$$

Leaf shrinkage corresponding to each size, also called dimensional shrinkage, was calculated per plant species, sampling site and moisture content level using the following formula (Hiziroglu 2007):

$$
\mathrm{R}(\%)=\frac{\text { size difference }}{\text { initial size }} \times 100
$$

Total leaf shrinkage was also calculated using the sum of the three dimensional shrinkages for each species.

All weights were measured at the laboratory with a Kern ${ }^{\circledR}$ ALJ 120-4 balance with a maximum of $120 \mathrm{~g}$ and accuracy to $0.1 \mathrm{mg}$. Length, width and thickness measurements were carried out using a digital electronic caliper Powerfix ${ }^{\circledR}$ 0-150 mm Z11155.

\section{Statistical analysis}

Species data were analyzed for species and sampling site effects using one-way ANOVA test, at 95 \% confidence level, in IBM Statistical Package for Social Sciences (SPSS). Pairwise comparisons of means were performed using Duncan's test.

\section{Results and discussion}

\section{Dimensional shrinkages}

In response to water loss, leaves and needles shrunk. This shrinkage was globally more visible thicknesswise than in the other directions (Table 2). This result is in accordance with Bacelar et al. (2004), which attributed the leaf shrinkage primarily to the thickness decrease. The highest thickness shrinkage values were recorded at $P$. pinea (48.07\%), $P$. pinaster $(45.23 \%)$ and at one site (Dardara) with respect to P. canariensis (43.00\%) and P. lentiscus (45.60\%). Otherwise, the lowest values belonged to C. salviifolius (19.81\%) and P. canariensis at two sites (Ahl Srif and Bellota, 10.93 and $4.53 \%$ respectively). In the thickness direction, leaves of most species exceeded $25 \%$ except for C. salviifolius and $P$. canariensis at two sites (Ahl Srif and Bellota).

Shrinkages widthwise and lengthwise were almost equal except for pine needles, leaves of C. albidus, C. monspeliensis, P. lentiscus and Q. suber, where shrinkage widthwise was greater than shrinkage lengthwise. In the widthwise, the leaves of C. siliqua (4.47 \%), $V$. tinus $(4.90 \%)$ and oak species ( $5 \%)$ were the samples that retracted least, whilst generally pine needles shrunk most (15-34 \%). This shrinkage was $<15 \%$ in most species 
Table 2 Leaf shrinkage

\begin{tabular}{|c|c|c|c|c|c|c|c|}
\hline Species & Site & $\begin{array}{l}\text { Shrinkage } \\
\text { thicknesswise } \\
(\%)\end{array}$ & $\begin{array}{l}\text { Shrinkage } \\
\text { widthwise } \\
\text { (\%) }\end{array}$ & $\begin{array}{l}\text { Shrinkage } \\
\text { lengthwise } \\
(\%)\end{array}$ & $\begin{array}{l}\text { Total } \\
\text { shrinkage } \\
\text { (\%) }\end{array}$ & SD & $\mathrm{CV}$ \\
\hline \multirow[t]{3}{*}{ A. unedo } & Souk L'Qolla & $28.49 \pm 4.25$ & $6.35 \pm 1.01$ & $6.30 \pm 0.87$ & 41.15 & 8.20 & 19.93 \\
\hline & Dardara & $38.00 \pm 2.84$ & $5.84 \pm 0.40$ & $4.93 \pm 0.52$ & 48.77 & 6.88 & 14.12 \\
\hline & Average & $33.68 \pm 2.78$ & $6.08 \pm 0.49$ & $5.55 \pm 0.51$ & 45.31 & 8.15 & 17.99 \\
\hline \multirow[t]{3}{*}{ C. siliqua } & Ahl Srif & $35.43 \pm 2.50$ & $3.60 \pm 0.33$ & $5.43 \pm 0.33$ & 44.46 & 5.46 & 12.28 \\
\hline & Souk L'Qolla & $39.38 \pm 1.97$ & $5.51 \pm 1.60$ & $4.33 \pm 0.56$ & 49.23 & 6.14 & 12.48 \\
\hline & Average & $37.23 \pm 1.67$ & $4.47 \pm 0.77$ & $4.93 \pm 0.34$ & 46.63 & 6.01 & 12.90 \\
\hline C. albidus & Souk L'Qolla & $34.99 \pm 1.86$ & $11.58 \pm 1.25$ & $8.69 \pm 1.20$ & 55.26 & 2.79 & 5.05 \\
\hline C. crispus & Ahl Srif & $27.14 \pm 3.53$ & $6.53 \pm 1.00$ & $6.24 \pm 1.95$ & 39.92 & 5.16 & 12.93 \\
\hline \multirow[t]{5}{*}{ C. monspeliensis } & Ahl Srif & $33.63 \pm 5.37$ & $14.85 \pm 3.15$ & $7.52 \pm 0.49$ & 56.01 & 18.46 & 32.96 \\
\hline & Souk L'Qolla & $26.63 \pm 6.35$ & $20.07 \pm 4.52$ & $8.05 \pm 1.12$ & 54.74 & 27.32 & 49.91 \\
\hline & Tanaqoub & $17.92 \pm 3.42$ & $12.35 \pm 2.94$ & $6.37 \pm 0.89$ & 36.64 & 12.34 & 33.67 \\
\hline & Bellota & $34.16 \pm 8.80$ & $9.13 \pm 1.76$ & $7.77 \pm 0.64$ & 51.06 & 20.15 & 39.47 \\
\hline & Average & $27.82 \pm 3.14$ & $14.32 \pm 1.77$ & $7.41 \pm 0.41$ & 49.55 & 20.50 & 41.37 \\
\hline C. salviifolius & Larache & $19.81 \pm 3.14$ & $11.40 \pm 2.05$ & $9.62 \pm 0.99$ & 40.82 & 11.81 & 28.93 \\
\hline \multirow[t]{4}{*}{ P. canariensis } & Ahl Srif & $10.93 \pm 1.43$ & $14.29 \pm 4.15$ & $0.93 \pm 0.09$ & 26.14 & 4.68 & 17.89 \\
\hline & Dardara & $43.00 \pm 2.82$ & $20.67 \pm 1.28$ & $1.17 \pm 0.20$ & 64.83 & 5.39 & 8.31 \\
\hline & Bellota & $4.53 \pm 2.43$ & $5.25 \pm 2.98$ & $1.81 \pm 0.56$ & 11.59 & 2.86 & 24.65 \\
\hline & Average & $25.36 \pm 5.56$ & $15.22 \pm 2.28$ & $1.27 \pm 0.18$ & 41.85 & 24.97 & 59.67 \\
\hline P. pinaster & Souk L'Qolla & $45.23 \pm 1.26$ & $27.63 \pm 2.54$ & $1.63 \pm 0.32$ & 74.49 & 8.02 & 10.77 \\
\hline P. pinea & Larache & $48.07 \pm 3.02$ & $34.43 \pm 3.51$ & $3.39 \pm 1.07$ & 85.89 & 2.41 & 2.80 \\
\hline \multirow[t]{4}{*}{ P. lentiscus } & Ahl Srif & $36.88 \pm 3.56$ & $6.50 \pm 0.68$ & $2.51 \pm 0.29$ & 45.88 & 7.38 & 16.09 \\
\hline & Souk L'Qolla & $35.83 \pm 1.17$ & $6.10 \pm 1.23$ & $3.63 \pm 0.71$ & 45.56 & 6.06 & 13.30 \\
\hline & Dardara & $45.60 \pm 4.17$ & $22.22 \pm 3.42$ & $4.66 \pm 0.97$ & 72.48 & 6.29 & 8.68 \\
\hline & Average & $38.67 \pm 1.92$ & $10.28 \pm 2.00$ & $3.46 \pm 0.41$ & 52.41 & 13.47 & 25.70 \\
\hline Q. coccifera & Bellota & $26.12 \pm 3.14$ & $4.71 \pm 0.68$ & $3.34 \pm 1.20$ & 34.17 & 8.30 & 24.30 \\
\hline \multirow[t]{5}{*}{ Q. suber } & Larache & $22.89 \pm 2.57$ & $3.15 \pm 0.55$ & $2.04 \pm 0.58$ & 28.09 & 5.75 & 20.49 \\
\hline & Ahl Srif & $30.27 \pm 2.99$ & $6.39 \pm 0.82$ & $2.63 \pm 0.77$ & 39.29 & 6.10 & 15.52 \\
\hline & Tanaqoub & $27.61 \pm 2.31$ & $5.82 \pm 1.91$ & $2.59 \pm 0.27$ & 36.02 & 9.54 & 26.49 \\
\hline & Dardara & $25.55 \pm 5.04$ & $6.03 \pm 0.72$ & $2.48 \pm 0.17$ & 34.07 & 11.69 & 34.32 \\
\hline & Average & $26.63 \pm 1.58$ & $5.26 \pm 0.59$ & $2.43 \pm 0.27$ & 34.32 & 8.72 & 25.42 \\
\hline V.tinus & Bellota & $34.93 \pm 2.52$ & $4.90 \pm 0.54$ & $4.77 \pm 0.93$ & 44.60 & 5.11 & 11.46 \\
\hline
\end{tabular}

Measurements of the shrinkages thicknesswise, widthwise and lengthwise \pm standard error. Total leaf shrinkage per species given for each site followed by standard deviation and coefficient of variation

except for $P$. pinea, $P$. pinaster and $P$. canariensis at one site (Dardara). In the lengthwise, leaf shrinkage of $P$. canariensis $(\sim 1 \%)$ and $P$. pinaster (1.63 \%) was the lowest, whereas it was more enhanced in Cistus species (6.24-9.62\%).

Total shrinkages of Cistus species were close and varied from $39.92 \%$ (Cistus crispus) to $55.26 \%$ (Cistus albidus). Pinus pinea needles had the highest total shrinkage values (85.89\%), while Q.coccifera and Q. suber indicated the lowest values (34.17 and $34.32 \%$ respectively) (Table 2). In the thickness direction, needles of $P$. pinea, $P$. pinaster and $P$. canariensis (Dardara) were almost similar. Pinus pinaster and P. canariensis showed also close leaf shrinkage lengthwise $(\sim 1 \%)$. Oak species leaves displayed almost the same values concerning total shrinkage ( 34 \%), shrinkage thicknesswise $(\sim 26 \%)$, widthwise ( $5 \%)$ and lengthwise ( 3 \%). 
As regards the species that were harvested in several sites (Table 1), one-way ANOVA, at $95 \%$ confidence level, was performed to test the site effect on total leaf shrinkage. The test showed no significant effect for most of these species with $\mathrm{p}$ values varying from 0.128 (A. unedo) to 0.354 (C. monspeliensis) except for P. canariensis and P. lentiscus, for which $p$ value $=0.000$. The three sites where $P$. canariensis needles were sampled indicated all statistical differences. This is due to anatomical differences in P. canariensis needles, owing to the environmental conditions variability (Grill et al. 2004). Regarding the leaves of $P$. lentiscus, only one site (Dardara) was significantly different from the other sites (Ahl Srif and Souk L'Qolla), considered similar. According to Barazani et al. (2003), there is a high polymorphism in P. lentiscus leaves. This warrants the significant shrinkage differences observed between certain sites.

The evolution of leaf shrinkage in the direction of thickness, width and length (dimensional shrinkage) according to leaf moisture content is shown in Figs. 1, 2. Leaf shrinkages related to $P$. canariensis and $P$. lentiscus, which are significantly influenced by site effect, are presented in such a way as to cover all the statistically different sites. Leaf shrinkage in the thickness direction was by far the most dominant with regard to the shrinkages widthwise or lengthwise, whatever the species and the site (Figs. 1, 2). In the thickness direction, leaf shrinkage is even more important that the moisture content is low. In any case, shrinkage thicknesswise increased quickly at the beginning and then stabilized once a determined threshold is reached. Otherwise, the shrinkages lengthwise and widthwise generally merged and remained minors. Yet, the shrinkage widthwise got closer to the shrinkage thicknesswise for pine needles (all sites) (Figs. 1, 2), while in $C$. salviifolius leaves, the three shrinkages evolved jointly one beside the other, despite the persistent dominance of the shrinkage thicknesswise (Fig. 1).

The moisture content threshold below which the shrinkage thicknesswise stabilizes depended on the species, though some species had almost the same threshold. Indeed, all Cistus species displayed close thresholds (8-13\%). Pinus pinaster and P. pinea shrinkages both stabilized below the same threshold ( 83 and $85 \%$ respectively). Species such as A. unedo, Q. coccifera and $V$. tinus showed close thresholds although they are not within the same genus. Pine needles had particularly the greatest thresholds (61-98\%), whilst Cistus species exhibited the lowest ones (8-13\%).

\section{Comparison with wood shrinkage}

The anisotropic nature of timber leads to a shrinkage difference depending on the direction considered (Nepveu 1994). The tangential, radial and longitudinal anisotropy directions of timber correspond respectively to the thickness, width and length directions of the leaf. The shrinkage thicknesswise dominance over the others dimensional shrinkages is comparable to the dominance of the tangential shrinkage in wood over the radial and longitudinal shrinkages. Furthermore, the shrinkage widthwise is generally either greater or close to the shrinkage lengthwise, which is quite similar to the shrinkage behavior in wood. We conclude that the leaf behaves similarly to wood in response to drying.

\section{Forest fuels classification based on total leaf shrinkage}

The comparison between total leaf shrinkage values related to the 13 forest fuels, through one-way ANOVA and Duncan's multiple comparison test (95\% confidence 


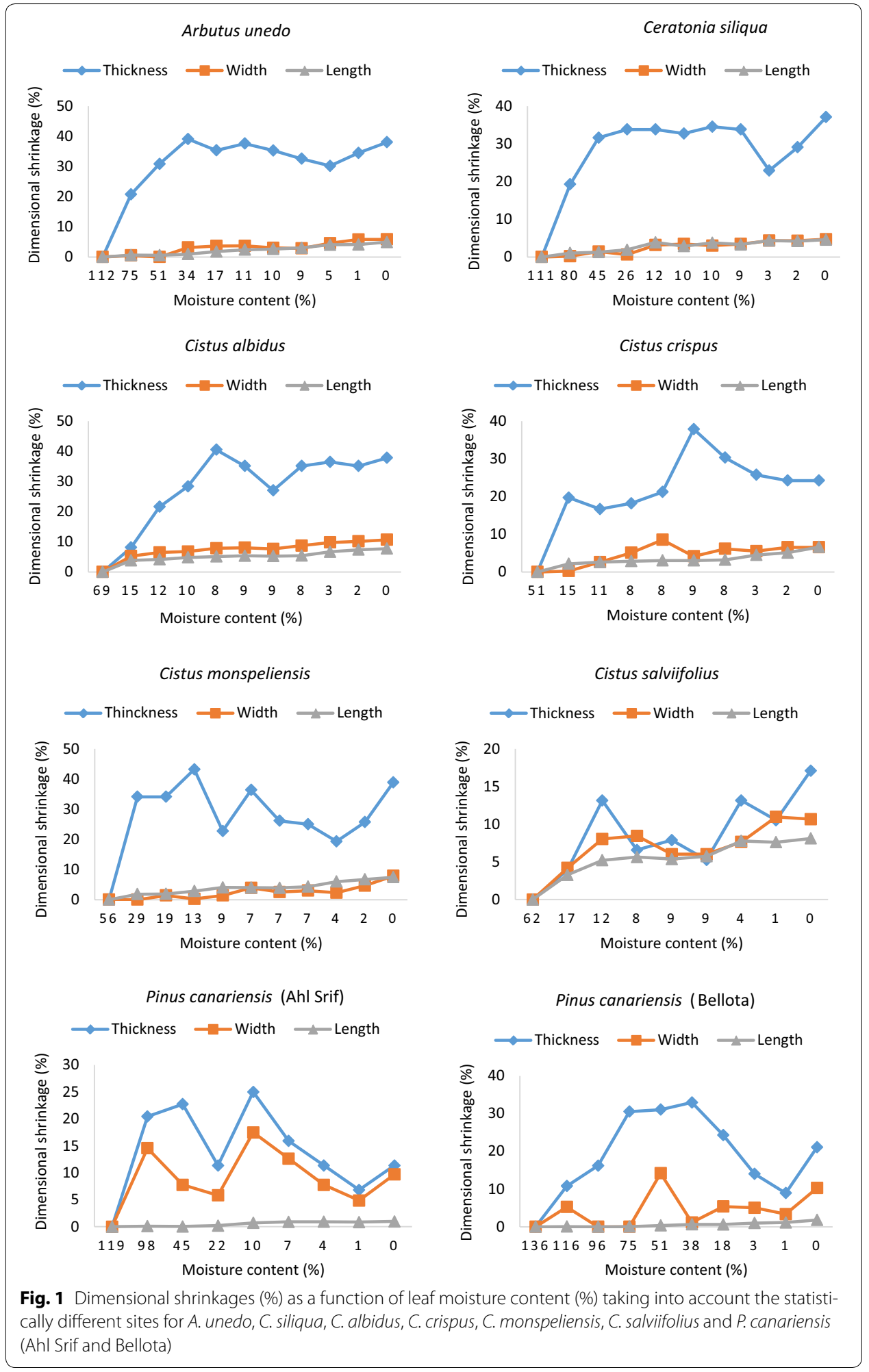

level) showed highly significant statistical difference among the total foliar shrinkage values of the species examined (Table 3), which formed 3 levels of significance (Table 4). Most species fell into medium shrinkage category, whilst oak species were classified as low shrinkage species. Pinus pinaster and $P$. pinea showed greater leaf shrinkage values 


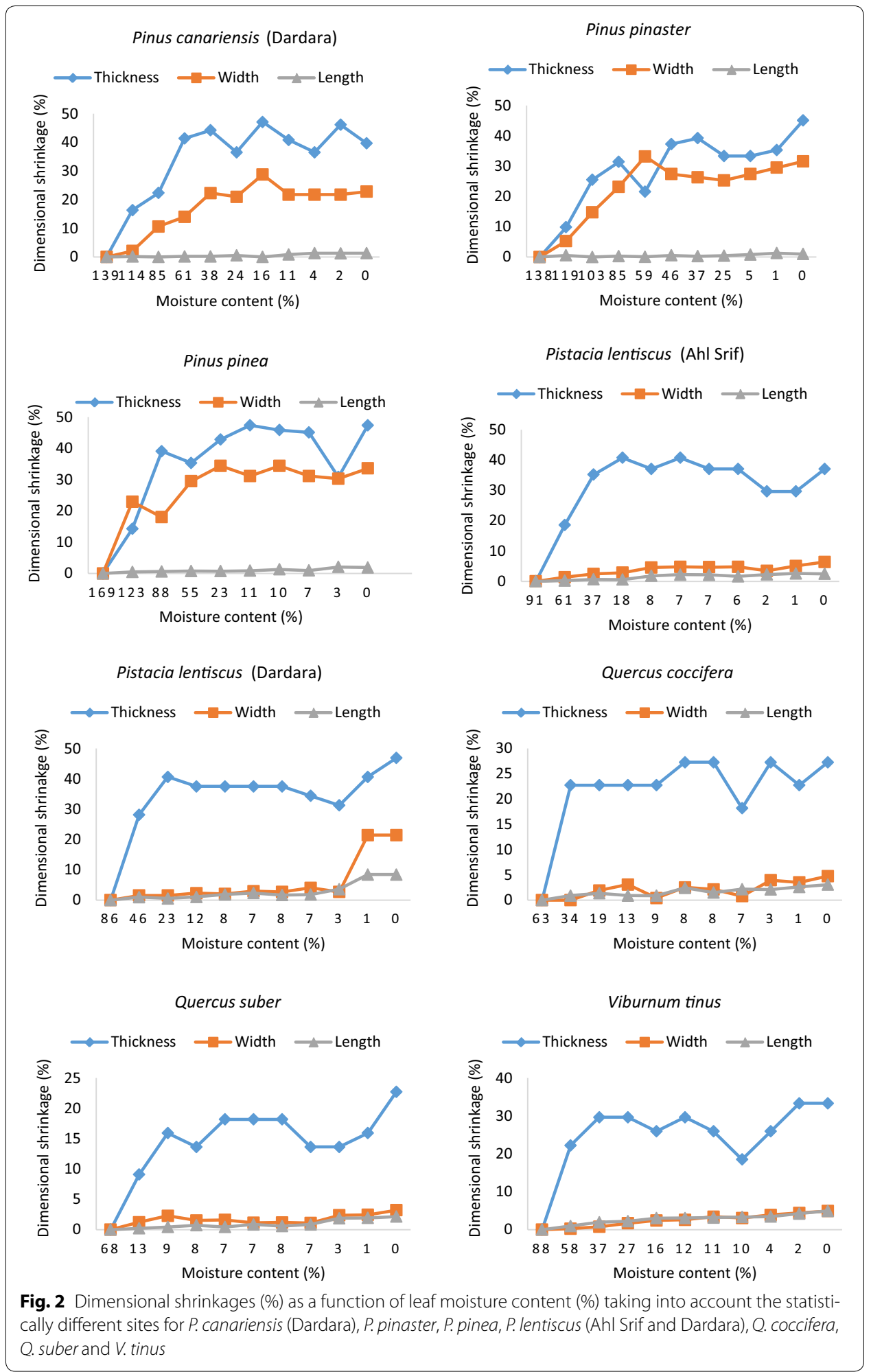

that enabled them to achieve the high shrinkage category (Table 4). Because of the significant site effect noted in P. canariensis and P. lentiscus, their leaf shrinkage rankings are therefore site-dependent and are not included in the classification table. Pinus canariensis was considered as less shrinkable species at Ahl Srif and Bellota (26.14 and $11.59 \%$ 
Table 3 Analysis of variance of total leaf shrinkage values of 13 forest fuels

\begin{tabular}{llrlll}
\hline Source of variation & SS & \multicolumn{1}{c}{$\boldsymbol{d f}$} & MS & $\boldsymbol{F}$ test & $\boldsymbol{F}$ \\
\hline Method & $16,596.204$ & 12 & 1383.017 & 0.000 significant & 7.004 \\
Residual error & $22,906.660$ & 116 & 197.471 & & \\
Totals & $39,502.864$ & 128 & & & \\
\hline
\end{tabular}

Table 4 Some forest fuels classification according to their leaf total shrinkage

\begin{tabular}{lll}
\hline Shrinkage class & Species & Total shrinkage (\%) \\
\hline High shrinkage & P. pinea & 85.89 \\
S $65 \%$ & P. pinaster & 74.49 \\
Medium shrinkage & C. albidus & 55.26 \\
$35<S \leq 65 \%$ & C. monspeliensis & 49.55 \\
& C. siliqua & 46.63 \\
& A. unedo & 45.30 \\
& V.tinus & 44.60 \\
& C. salviifolius & 40.82 \\
Low shrinkage & C. crispus & 39.92 \\
S $35 \%$ & Q. suber & 34.32 \\
\hline
\end{tabular}

respectively), but at Dardara, it can be regarded as moderately shrinkable (64.83 \%). $P$. lentiscus leaves were classified as highly shrinkable (72.48 \%) at Dardara. However, at Ahl Srif they were ranked as moderately shrinkable (45.88 \%).

\section{Leaf shrinkage versus drought-coping mechanisms and plant flammability}

Leaf shrinkage, since it is primarily related to thickness variation, is determined by the amount of water inside the leaf (Bacelar et al. 2004; Bussotti et al. 2002) and the ability of the leaf cells to lose turgor after a water loss under drought conditions (Bussotti et al. 2002). Indeed, water stress induces an increase in cell wall elasticity (Martínez et al. 2007; Piñol et al. 1998) in preparation for leaf cells contraction (Martínez et al. 2007), resulting in leaf shrinkage. However, in order to cope with drought conditions, some adaptive mechanisms can mitigate this response (Aranda et al. 2014; Bacelar et al. 2004; Bussotti et al. 2002). Besides the stomatal regulation, sclerophylly is among the most common drought-coping plant feature (Aranda et al. 2014). Sclerophylly is enhanced by building parenchymatous tissues and the upper cuticular layer (Bacelar et al. 2004; Bussotti et al. 2002), increasing thereby the leaf tissue density (Aranda et al. 2014; Bussotti et al. 2002) and avoiding desiccation (Aranda et al. 2014; Pardos et al. 2009; Bacelar et al. 2004; Bussotti et al. 2002). The increased tissue density and water conservation both help to limit leaf shrinkage, since the parenchymatous tissues act as reinforcement support for the leaf internal components (Grill et al. 2004) and the water retention maintains the leaf turgor (Bacelar et al. 2004).

Indeed, the sclerophyllous character of the leaves of oak species made them least shrinkable as shown in the shrinkage classification table (Table 4). This feature enables the oak leaves to remain turgid as possible and therefore reduces the shrinkage potential. The leaves of Cistus species are less sclerophyllous than those of oaks, though they 
have a relatively thick cuticle that can mitigate the hydric stress effects (Aranda et al. 2014; Pardos et al. 2009; Bacelar et al. 2004; Bussotti et al. 2002). Therefore, Cistus leaves are classified as moderately shrinkable. The high shrinkage potential of $P$. pinaster and $P$. pinea can be explained by the prominence of two main parameters. Pine needles have, first, thin cuticle, allowing increased cuticular transpiration (Aranda et al. 2014; Pardos et al. 2009) and, secondly, pine needles are less sclerophyllous, depriving thereby the leaf of a mechanism limiting uncontrolled transpiration (Grill et al. 2004). This results in high desiccation susceptibility of the needles (Grill et al. 2004), which increases therefore the shrinkage potential (Bacelar et al. 2004). Otherwise, $P$. canariensis needles are less shrinkable than the other pine needles (Table 2). Pinus canariensis needles distance themselves from other pine needles through their particular epistomatal chamber, with a narrow aperture, where wax tubes are very dense and their small stomata compared to other pine species (Grill et al. 2004). These characteristics are responsible for the stomata occlusion (Jimenez et al. 2000; Zellnig et al. 2002). Thus, this arrangement of stomata cells inhibits transpiration (Zellnig et al. 2002) in order to limit water loss and then mitigate leaf shrinkage (Bacelar et al. 2004; Bussotti et al. 2002). In addition, cuticular transpiration in P. canariensis needles is the lowest among Pinus species (Pardos et al. 2009), showing even more fitness to keep water inside the needles, decreasing thereby the shrinkage potential (Bussotti et al. 2002). Furthermore, leaf shrinkage in P. canariensis varies significantly from a site to another. This result is in accordance with the following reports Climent et al. (2002), Grill et al. (2004), López et al. (2007) and Pardos et al. (2009) that highlighted a variation in the physiological response to hydric stress of $P$. canariensis needles from one site to the other. According to Grill et al. (2004), this is due to the variable anatomy of $P$. canariensis needles, which changes depending on environmental conditions.

Leaf shrinkage gives an idea on the potential of the leaf to change its dimensions and particularly its surface area-to-volume ratio when it dries and becomes litter. This potential is even more important to assess when we know that litter is the most vulnerable forest fuel towards wildfire. Indeed, litter is the forest fuel that has the greatest ignitability and combustibility (Liodakis et al. 2008). Afterward, the positive dimensional shrinkage values (Table 2) showed that all the dimensions studied decreased substantially-mainly thickness - as the drying and according to Hachmi's et al. (2011a) SVR formula, SVR would have increased as a result. Species ranking in terms of their leaf shrinkage implies a ranking of the potential SVR variation range and subsequently help in wildfire prediction and fire hazard assessment (Fernandes and Rego 1998; Hachmi et al. 2011a; Hernando et al. 1995; Brown 1970; Rothermel 1983). In addition, since SVR is a characteristic favorable to flammability (Dimitrakopoulos and Panov 2001; Fernandes and Rego 1998; Hachmi et al. 2011b; Papió and Trabaud 1990; Pereira et al. 1995), the leaf shrinkage ranking of a species should be positively correlated with its corresponding flammability class. Our results showed that comparisons between shrinkage class of a plant species and its flammability class as reported in the literature revealed two different scenarios. Shrinkage classes of species such as A. unedo, C. siliqua, C. albidus, C. crispus, $C$. monspeliensis, $C$. salviifolius and $V$. tinus provided insights into their corresponding flammability classes as suggested by Dimitrakopoulos (2001), Dimitrakopoulos and Papaioannou (2001), Liodakis et al. (2008) and Hachmi et al. (2011b). Although 
the leaves of Quercus species were less shrinkable, they were regarded as flammable by the latter reports. This may be due to the numerous parameters involved in the determination of the species flammability, such as ash content, bulk density, fuel loading by size class and heat content (Dimitrakopoulos and Panov 2001; Papió and Trabaud 1990; White and Zipperer 2010; Behm et al. 2004). As leaf shrinkage in P. canariensis and $P$. lentiscus was site-dependent, their flammability would be also influenced by site effect and even related to other flammability parameters.

\section{Conclusion}

This study focuses on leaf shrinkage-in the directions of thickness, width and lengthin relation to moisture content; and the classification of forest fuels based on their leaf potential shrinkage. Future research prospects are conceivable for the extension of the shrinkage database in more plant species and for further clarification of the relation between leaf shrinkage and plant flammability. We conclude from this work that shrinkage, whether in timber or in leaf, behaves in the same way and the shrinkages in the three directions maintain the same reporting relationships between each other. Besides, leaf shrinkage raises when the moisture content decreases. Pinus canariensis needles are globally distinguished from other pine needles by low shrinkage and therefore show more drought-resistance ability, in accordance with the features of these needles as reported in the literature. Species of the genera Cistus and Quercus are respectively moderately and less shrinkable by dint of their mechanisms of drought tolerance.

\section{Authors' contributions}

$\mathrm{MH}, \mathrm{MY}$ and MD conceived the research work and contributed to the interpretation of the whole results. SE harvested the leaves samples from the field and performed the measurements, carried out the analysis and interpretation of the experimental results, and drafted the manuscript. All authors read and approved the final manuscript.

\section{Author details}

${ }^{1}$ Institut Agronomique et Vétérinaire Hassan II, BP 6202, Rabat-Instituts, Rabat, Morocco. ${ }^{2}$ Ecole Nationale Forestière d'Ingénieurs, BP 511, Tabriquet, 11015 Salé, Morocco.

Acknowledgements

We are grateful to Mr. Rhaz Mohammed, laboratory technician, for his participation in the laboratory measurements.

Competing interests

The authors declare that they have no competing interests.

Received: 2 June 2016 Accepted: 22 July 2016

Published online: 02 August 2016

\section{References}

Alexander ME, Cruz MG (2012) Assessing the effect of foliar moisture on the spread rate of crown fires. Int J Wildland Fire. doi:10.1071/WF12008

Aranda I, Ramírez-Valiente JA, Rodríguez-Calcerrada J (2014) Características funcionales que influyen en la respuesta a la sequía de las especies del género Quercus: variación inter- e intra-específica. Ecosistemas 23(2):27-36. doi:10.7818/ ECOS.2014.23-2.05

Bacelar EA, Correia CM, Moutinho-pereira JM, Gonçalves BC, Lopes JI, Torres-Pereira JMG (2004) Sclerophylly and leaf anatomical traits of five field-grown olive cultivars growing under drought conditions. Tree Physiol 24:233-239

Barazani O, Dudai N, Golan-Goldhirsh A (2003) Comparison of Mediterranean Pistacia lentiscus genotypes by random amplified polymorphic DNA, chemical, and morphological analyses. J Chem Ecol 29:1939-1952. doi:10.102 3/A:1024862614345

Behm AL, Duryea ML, Long AJ, Zipperer WC (2004) Flammability of native understory species in pine flatwood and hardwood hammock ecosystems and implications for the wildland-urban interface. Int J Wildland Fire 13:355-365. doi:10.1071/WF03075

Brown J (1970) Ratios of surface area to volume for common fine fuels. For Sci 16:101-105

Búrquez A (1987) Leaf thickness and water deficit in plants: a tool for field studies. J Exp Bot 38(186):109-114

Bussotti F, Bettini D, Grossoni P, Mansuino S, Nibbi R, Soda C, Tani C (2002) Structural and functional traits of Quercus ilex in response to water availability. Environ Exp Bot 47:11-23 
Climent J, Gil J, Pérez L, Pardos E (2002) Effecto de la procedencia en la supervivencia de plantulas de Pinus canariensis Sm. en medio arido. Investig Agrar Sist Recur 11:171-180

Dimitrakopoulos AP (2001) A statistical classification of Mediterranean species based on their flammability components. Int J Wildland Fire 10:113-118. doi:10.1071/WF01004

Dimitrakopoulos AP, Panov PI (2001) Pyric properties of some dominant Mediterranean vegetation species. Int J Wildland Fire 10:23-27. doi:10.1071/WF01003

Dimitrakopoulos AP, Papaioannou KK (2001) Flammability assessment of Mediterranean forest fuels. Fire Technol 37:143-152

Fernandes PM, Rego FC (1998) A new method to estimate fuel surface area-to-volume ratio using water immersion. Int J Wildland Fire 8:121-128. doi:10.1071/WF9980121

Grill D, Tausz M, Pöllinger U, Jiménez MS, Morales D (2004) Effects of drought on needle anatomy of Pinus canariensis. Flora 199:85-89. doi:10.1078/0367-2530-00137

Hachmi M, Sesbou A, Benjelloun H, Bouanane F (2011a) Alternative equations to estimate the surface-to-volume ratio of different forest fuel particles. Int J Wildland Fire 20:648-656. doi:10.1071/WF09042

Hachmi M, Sesbou A, Benjelloun H, El Handouz N, Bouanane F (2011b) A simple technique to estimate the flammability index of Moroccan forest fuels. J Combust. doi:10.1155/2011/263531

Hernando C, Guijarro M, Santos JA (1995) Determinacion de la relacion superficie/volumen de las aciculas muertas, Investig Agrar Sist Recur Forest 4(1):73-85

Hiziroglu S (2007) Dimensional changes in wood. Oklahoma Coop. Ext. Serv. NREM-5009. Division of Agricultural Sciences and Natural Resources, Oklahoma State University, pp. 1-4

Jimenez MS, Zellnig G, Stabentheiner E, Peters J, Morales D, Grill D (2000) Structure and ultrastructure of Pinus canariensis needles. Flora 195:228-235

Liodakis S, Kakardakis T, Tzortzakou S, Tsapara V (2008) How to measure the particle ignitability of forest species by TG and LOI. Thermochim Acta 477(2008):16-20

López L, Zehavi R, Climent A, Gil J (2007) Contrasting ecotypic differentiation for growth and survival in Pinus canariensis (Pinaceae). Aust J Bot 55:1-11

Martínez JP, Silva H, Ledent JF, Pinto M (2007) Effect of drought stress on the osmotic adjustment, cell wall elasticity and cell volume of six cultivars of common beans (Phaseolus vulgaris L.). Eur J Agron 26:30-38. doi:10.1016/j. eja.2006.08.003

Nepveu G (1994) Variabilité. In: Jodin P (ed) Le bois matériau d'ingénierie. Nancy, A.R.BO.LOR, pp 127-182

Papió C, Trabaud L (1990) Structural characteristics of fuel components of five Mediterranean shrubs. For Ecol Manag 35:249-259

Pardos M, Calama R, Climent J (2009) Difference in cuticular transpiration and sclerophylly in juvenile and adult pine needles relates to the species-specific rates of development. Trees 23:501-508. doi:10.1007/s00468-008-0296-6

Pausas JG, Alessio GA, Moreira B, Corcobado G (2012) Fires enhance flammability in Ulex parviflorus. New Phytol 193:18-23

Pellizzaro G, Duce P, Ventura A, Zara P (2007) Seasonal variations of live moisture content and ignitability in shrubs of the Mediterranean basin. Int J Wildland Fire 16:633-641. doi:10.1071/WF05088

Pereira JMC, Sequeira NMC, Carreiras JMB (1995) Structural properties and dimensional relations of some Mediterranean shrub fuels. Int J Wildland Fire 5(1):35-42. doi:10.1071/WF9950035

Piñol J, Filella I, Ogaya R, Peñuelas J (1998) Ground-based spectroradiometric estimation of live fine fuel moisture of Mediterranean plants. Agric For Meteorol 90:173-186. doi:10.1016/S0168-1923(98)00053-7

Rothermel RC (1983) How to predict the spread and intensity of forest and range fires. USDA Forest Service Intermountain Forest Range Experiment Station. Research Paper. General Technical Report. INT-143, 161 pp

Valette JC (1990) Inflammabilités des espèces forestières méditerranéennes. Conséquences sur la combustibilité des formations forestières. Revue Forestière Française XLII - no. sp. 1990

White RH, Zipperer WC (2010) Testing and classification of individual plants for fire behaviour: plant selection for the wildland-urban interface. Int J Wildland Fire 19:213-227. doi:10.1071/WF07128

Zellnig G, Peters J, Jimenez MS, Morales D, Grill D, Perktold A (2002) Three-dimensional reconstruction of the stomata complex in Pinus canariensis needles using serial sections. Plant Biol 4:70-76. doi:10.1055/s-2002-20438

\section{Submit your manuscript to a SpringerOpen ${ }^{\circ}$ journal and benefit from:}

- Convenient online submission

- Rigorous peer review

- Immediate publication on acceptance

Open access: articles freely available online

- High visibility within the field

- Retaining the copyright to your article

Submit your next manuscript at $\boldsymbol{\nabla}$ springeropen.com 